\title{
Mechanisms underlying the effect of commercial starter cultures and a native yeast on ochratoxin A production in meat products
}

\author{
Sana Meftah ${ }^{\mathrm{a}}$, Salwa Abid ${ }^{\mathrm{b}}$, Teresa Dias ${ }^{\mathrm{a}}$, Paula Rodrigues ${ }^{\mathrm{a}, *}$ \\ ${ }^{a}$ Centro de Investigação de Montanha, Instituto Politécnico de Bragança, Campus de Santa Apolónia, 5300-253 Bragança, Portugal \\ ${ }^{\mathrm{b}}$ Laboratory for Research on Biologically Compatible Compounds, Faculty of Dentistry, Rue Avicenne, 5019, Monastir, Tunisia
}

\section{A R T I C L E I N F O}

\section{Keywords:}

Mycotoxins

Biocontrol

Food safety

Pork meat products

\begin{abstract}
A B S T R A C T
Processed meat products are of worldwide importance, but they are highly prone to fungal and ochratoxin A (OTA) contamination. In previous studies, several Lactic Acid Bacteria (LAB) and yeasts have been tested as biocontrol agents against $P$. nordicum growth and OTA production in meat products, with promising results. However, A. westerdijkiae has been poorly studied for this matrix.

The aim of this work was to evaluate in vitro the mechanisms underlying the effects of a commercial starter culture and of a meat-native Candida zeylanoides strain on the growth and OTA production of $P$. nordicum and A. westerdijkiae, by co-culture in ham and sausage-based media under different conditions.

In ham medium, $C$. zeylanoides live cells, cell broth and diffused compounds significantly inhibited OTA production by $P$. nordicum, but live cells of the starter culture significantly increased it. For $A$. westerdijkiae strong and significant stimulation was observed by direct contact in both media.

In conclusion, ochratoxigenic fungi do not all respond to antagonistic microorganisms in the same way. This study sheds some light on the mechanisms behind the different effects of microorganisms.
\end{abstract}

\section{Introduction}

Mycotoxins are natural substances produced as secondary metabolites of several filamentous fungi. They have worldwide distribution and affect a significant part of food and feed products. Mycotoxins pose a health risk to humans and animals due to their harmful biological properties. They also have a very wide economic impact resulting from health and veterinary care costs, reduction in livestock production, investment in research to reduce risks of mycotoxin problems (Zain, 2011).

Processed meat products such as dry-cured ham, fermented sausage and others are foods of major importance in several European countries, both nutritionally and economically. However, due to their characteristics, they are highly exposed to mycotoxin producing fungi.

Ochratoxin A (OTA) is the most significant mycotoxin found in processed meat products. Because it is strongly adapted to salt and protein-rich matrices and is moderately psychrotrophic, Penicillium nordicum has been associated with OTA contamination of these products, but Aspergillus westerdijkiae has been recently associated with high levels of OTA in meat products (Meftah, Abid, Dias, \& Rodrigues, 2018; Merla et al., 2018; Vipotnik, Rodríguez, \& Rodrigues, 2017).

The development of efficient strategies to avoid it from entering the food chain is on the top of research. One of the most promising strategies under study is to prevent its accumulation by creating the best conditions to inhibit OTA production. Several studies have reported Lactic Acid Bacteria (LAB) and yeasts as promising biocontrol agents (BCAs) against $P$. nordicum growth and OTA production in meat products (Andrade, Thorsen, Rodríguez, Córdoba, \& Jespersen, 2014; Iacumin, Manzano, Andyanto, \& Comi, 2017; Rodriguez et al., 2015; Simoncini, Virgili, Spadola, \& Battilani, 2014; Virgili et al., 2012), but only one of these studies has considered the effect of these microorganisms on A. westerdijkiae (Meftah et al., 2018).

The mechanisms by which BCAs affect fungal growth can be due to competition for nutrients and space (Hernández-Montiel, Ochoa, TroyoDiéguez, \& Larralde-Corona, 2010), production of hydrolytic enzymes or killer toxins (Masih \& Paul, 2002) and secretion of volatile compounds (Masoud, Poll, \& Jakobsen, 2005; Taczman-Brückner MohácsiFarkas, Balla \& Kiskó, 2005; Fialho, Toffano, Pedroso, Augusto, \& Pascholati, 2009; Fiori et al., 2014; Farbo et al., 2016). Several yeasts such as Debaryomyces hansenii, Hyphopichia burtonii and Candida zeylanoides were reported as strong inhibitors of $P$. nordicum growth in drycured ham and dry fermented sausage (Andrade et al., 2014; Nuñez et al., 2015; Virgili et al., 2012). Bacteria of the Pediococcus and Lactobacillus genera have also been studied as potential BCAs against fungi

\footnotetext{
* Corresponding author.

E-mail address: prodrigues@ipb.pt (P. Rodrigues).
} 
and mycotoxins in several food matrices, with inhibiting effects being observed (Abrunhosa et al., 2014; Ngang et al., 2015; Pereira et al., 2016).

Our group has previously studied the effect of a commercial starter culture composed by $\mathrm{LAB}, \mathrm{CNC}$ and $D$. hansenii and of several Portuguese dry-sausage endogenous yeasts on $P$. nordicum and $A$. westerdijkiae growth and OTA production ability in a Portuguese-style dryfermented sausage-based medium (Meftah et al., 2018). That study concluded that $A$. westerdijkiae was significantly stimulated to produce OTA in meat products by the native yeast $C$. zeylanoides and by the commercial starter culture. The same starter culture also stimulated OTA production by $P$. nordicum. The present work aimed to evaluate in vitro the mechanisms underlying the observed effects of the yeast and the starter culture on these ochratoxigenic fungi.

\section{Materials and methods}

\subsection{Microorganisms and inocula preparation}

\subsubsection{Yeasts and starter culture}

A strain of $C$. zeylanoides $(\mathrm{Cz})$ previously isolated from Portuguese traditional dry-fermented sausage and identified molecularly (Meftah et al., 2018) was sub-cultured from stock vials onto Potato Dextrose Agar (PDA, Liofilchem-ITALY) and incubated at $28^{\circ} \mathrm{C}$. The preparation of the pre-inoculum followed the procedure described by Meftah et al. (2018). Briefly, one colony from 3 day old cultures was suspended in Potato Dextrose Broth (PDB, Liofilchem-ITALY) and incubated at $28^{\circ} \mathrm{C}$ for $24 \mathrm{~h}$ in a rotary shaker $(120 \mathrm{rpm})$. Optical density of the suspension was determined by spectrophotometry at $600 \mathrm{~nm}$ wave length and an inoculum with approximately $10^{5}$ cells/mL was prepared for all assays. Cell concentration was estimated by interpolation of absorbance values measured at $600 \mathrm{~nm}$ using the relationship OD600 $=1.0$ corresponding to $3 \times 10^{7}$ cells $/ \mathrm{mL}$, as described by Day, Schneider, and Schneider (2004).

The commercial freeze-dried starter culture (Texel ${ }^{\circledR} \mathrm{ELCE} \mathrm{Br}$, Danisco) - composed of Pediococcus pentosaceus, Lactobacillus sakei, Staphylococcus carnosus, Staphylococcus xylosus and Debaryomyces hansenii - was also used. The freeze-dried starter culture $(0.01 \% \mathrm{w} / \mathrm{v})$ was inoculated in MRS (de Man, Rogosa, Sharpe) broth and incubated at $37^{\circ} \mathrm{C}$ for $24 \mathrm{~h}$. After that, $300 \mu \mathrm{L}$ were used to inoculate $150 \mathrm{~mL}$ of each meat extract media.

\subsubsection{Ochratoxigenic fungi}

Two species of OTA-producing fungi previously isolated from cured pork meat were used: A. westerdijkiae MUM16.142 (previously identified as strain 6B/131) and P. nordicum strain PN 44 (provided by Dr. Alicia Rodríguez, University of Extremadura, Spain). Fungi were inoculated in Malt Extract Agar (MEA, Liofilchem-ITALY) and incubated for 10 days at $25^{\circ} \mathrm{C}$ in the dark. After incubation, $2 \mathrm{~mL}$ of $0.05 \%$ Tween 80 solution were added to the culture and spores were rubbed to obtain a suspension, adjusted to $10^{7}$ spores/mL with the aid of a Neubauer counting chamber.

\subsection{Meat extract media preparation}

Media based on traditional sausage (TSM) and on ham (HM) were prepared as previously described in Meftah et al. (2018). Thirty grams of minced and lyophilized meat product were boiled in $1000 \mathrm{~mL}$ of distilled water (3\% meat) during $30 \mathrm{~min}$ and filtered through a cheese cloth. Meat extract was supplemented with $3 \% \mathrm{NaCl}$, and the volume was made up to $1000 \mathrm{~mL}$. Media were solidified with $2 \%$ of bacteriological agar (HiMedia), and were autoclaved at $121{ }^{\circ} \mathrm{C}$ for $15 \mathrm{~min}$.

$\mathrm{pH}$ was measured in triplicate with a pH-meter (METTLER TOLEDO) and corrected to 5.5 whenever necessary. Water activity was measured in triplicate using a water activity meter (Aqualab $4 \mathrm{TE}$ ).

\subsection{Mechanisms of action of biocontrol agents on fungal growth and OTA production}

To understand the mechanisms of action of the yeast $C$. zeylenoides and of the starter culture, fungi were co-inoculated with each test organism in different ways: 1) Effect of live cells was tested by incorporation of living cells in the medium, as positive control (the same condition as previously tested); 2) Effect of dead cells, was tested by incorporation of dead cells in the medium to determine if the effect on fungi was caused by a structural compound of the cell; 3) Effect of cellfree culture filtrate, by using the filtered broth where yeast/starter were previously grown as culture medium, to determine if the effect was caused by a compound previously produced by the yeast/starter and diffused to the medium; 4) Effect of diffusible compounds, fungi and yeast/starter where co-inoculated at a given distance, to study if the effect was caused by yeast/starter compounds being produced simultaneously with the fungus and being diffused towards the fungus; and 5) Effect of volatile compounds, fungi and yeast/starter were coinoculated without direct contact (cut culture medium), to verify if the microorganisms produced a volatile compound which influenced fungal growth and OTA production.

Two culture media - TSM and HM supplemented with $3 \% \mathrm{NaCl}-$ and one temperature $-20^{\circ} \mathrm{C}$ - were used with C. zeylanoides and starter culture. For all assays, each fungus was inoculated in $9 \mathrm{~cm}$ Petri dishes by two-point inoculation with $2 \mu \mathrm{L}$ spore suspension, in triplicate. After co-inoculation, all petri dishes were incubated at $20^{\circ} \mathrm{C}$ for 14 days.

\subsubsection{Effect of live cells, dead cells and cell-free broth}

C. zeylanoides and starter culture cell suspensions were prepared as previously described. The suspensions were inoculated in $300 \mathrm{~mL}$ of TSM and HM broths, and incubated in a rotary shaker $(120 \mathrm{rpm})$ at $28^{\circ} \mathrm{C}$ and at $37^{\circ} \mathrm{C}$, respectively. After $24 \mathrm{~h}$ of incubation, the broth was homogenized and divided into 2 portions. One portion was directly used for the live cells test. From the other portion, cells were centrifuged at $5000 \mathrm{rpm}$ for $10 \mathrm{~min}$. The resulting pellet was resuspended in $10 \mathrm{~mL}$ of sterile water and autoclaved at $120^{\circ} \mathrm{C}$ for $15 \mathrm{~min}$ to kill the cells. Dead cells were incorporated in new a portion of each media. The supernatant was further filtered with $0.22 \mu \mathrm{m}$ filters and used for the cell-free broth test. For each media portion, $2 \%$ of agar were aseptically added and the media with the live cells, dead cells and cell-free were distributed in $9 \mathrm{~cm}$ Petri dishes. Fungi were then inoculated as described.

\subsubsection{Effect of diffusible compounds}

To verify the influence of the yeast and the starter on fungal growth and OTA production by producing diffusible compounds, $2 \mu \mathrm{L}$ of spore suspension and $2 \mu \mathrm{L}$ of starter or $C$. zeylanoides were inoculated in opposite quadrants of the Petri dish.

\subsubsection{Effect of volatile compounds}

Twenty $\mathrm{mL}$ of each meat-based medium were plated in $9 \mathrm{~cm}$ petri dishes and then divided into 4 quadrants by cutting $3 \mathrm{~mm}$ lanes of agar perpendicularly, to avoid the contact of diffusible compounds potentially produced by test microorganisms with the fungus. Then, $2 \mu \mathrm{L}$ of spore suspension were added in two opposite quarters and $2 \mu \mathrm{L}$ of yeast or starter suspension were added to the other 2 opposite parts.

\subsection{Fungal growth assessment}

Fungal growth was determined throughout the incubation period every two days until colony coalescence, by orthogonal measurements of fungal colonies' diameter. At the end of incubation period, all Petri dishes were submitted to OTA analysis as described below. Petri dishes without test microorganisms (fungi only) were used as control. All tests were run in triplicate. 


\subsection{OTA analysis}

\subsubsection{OTA extraction}

OTA was extracted from plates after 14 days of incubation. Three agar plugs were removed from the inner, middle and outer areas of the colony, weighted and extracted with $1.5 \mathrm{~mL}$ of methanol as described by Bragulat et al. (2001). The agar plugs were maintained in methanol for $1 \mathrm{~h}$ and vortexed every $15 \mathrm{~min}$. The extracts were filtered by PTFE $0.2 \mu \mathrm{m}$ syringe filters and stored at $4^{\circ} \mathrm{C}$ until further analysis.

\subsubsection{OTA detection and quantification by High Performance Liquid Chromatography (HPLC)}

OTA was analysed as described by Meftah et al. (2018), with a High Performance Liquid Chromatography (HPLC) system equiped with: Smartline pump (1000, Knauer, Berlin, Germany), degasser system (Smartline manager 5000), auto-sampler (AS-2057, Jasco, Easton, MD, USA), and a fluorescence detector (FP-2020, Jasco) set to $\lambda$ ex $330 \mathrm{~nm}$ and $\lambda$ em $463 \mathrm{~nm}$. Data were analysed using Clarity 2.4 Software (DataApex, Prague, Czech Republic). The chromatographic separation was achieved using an isocratic elution with a C18 reverse-phase column (100 × $4.6 \mathrm{~mm}$, Merck Chromolith Performance, Darmstadt, Germany) operating at $35^{\circ} \mathrm{C}$ (7971 R Grace oven). The mobile phase consisted of an isocratic programme of water: acetonitrile: acetic acid (29.5:70:0.5, $\mathrm{v} / \mathrm{v} / \mathrm{v}$ ) and was pumped at $0.8 \mathrm{~mL} / \mathrm{min}$ for a total run time of $4 \mathrm{~min}$. The injection volume was $10 \mu \mathrm{L}$. Under these conditions, retention time for OTA was $2.2 \mathrm{~min}$.

\subsection{Statistical analysis}

Statistical analysis was performed using IBM $^{\circledast}$ SPSS $^{\circledast}$ Statistics v.22.0 software (Armonk, NY: IBM Corp.). For the comparison of means, samples were first tested for normal distribution by ShapiroWilk test and for homogeneity of variances by Levene's test. Since samples generally followed these criteria, t-student test and One-way ANOVA were used for comparison of means for 2-level variables and for more than 2-level variables, respectively. Post-hoc analyses were performed with Dunett test to create confidence intervals for differences between the mean of each factor level and the mean of a control group. In all cases, statistical significance was established at $p<0.05$.

\section{Results}

\subsection{Candida zeylanoides}

The results of fungal colony diameter of $P$. nordicum and A. westerdijkiae growth co-cultured with $C$. zeylanoides under different methods in TSM and $\mathrm{HM}$ with $3 \% \mathrm{NaCl}$ incubated at $20^{\circ} \mathrm{C}$ for 14 days are represented in Figs. 1 and 2. The results of OTA production are represented in Fig. 3. C. zeylanoides had a similar effect on growth of both $P$. nordicum and $A$. westerdijkiae. On the contrary, growth was generally increased with the incorporation of dead cells and of cell broth.

\subsection{Starter culture}

The results of $P$. nordicum and $A$. westerdijkiae, as well as OTA production relative to different methods of co-culture with the commercial starter culture, in TSM and $\mathrm{HM}$ with $3 \% \mathrm{NaCl}$ incubated at $20^{\circ} \mathrm{C}$ for 14 days are represented respectively in Figs. 4 and 5. Results of $P$. nordicum growth showed that the incorporated live cells reduced fungal growth significantly only in HM ( $\mathrm{p}<0.05)$, whereas cell broth and dead cells significantly stimulated fungal growth in both media. In the case of $A$. westerdijkiae growth, no significant effect was detected between control and test conditions and also between treatments. On the other hand, a significant stimulation of OTA production in both media occurred with the incorporation of live cells and in the volatiles test.

\section{Discussion and conclusion}

The mechanisms by which BCAs affect fungal growth and mycotoxin production are not always well understood, and this can be a limitation to their industrial use. BCAs have been reported to act by competition for nutrients and space (Hernández-Montiel et al., 2010; Zhao, Tu, Shao, Jing, \& Su, 2008), production of hydrolytic enzymes or killer toxins (Marquina, Barroso, Santos, \& Peinado, 2001; Masih \& Paul, 2002; Hernández et al., 2010) and, also frequently reported, secretion of volatile compounds (Masoud et al., 2005; Taczman-Brückner, Mohácsi-Farkas, Balla, \& Kiskó, 2005; Fialho et al., 2009; Fiori et al., 2014; Farbo et al., 2016). OTA adsorption to the yeast cell wall (Bejaoui, Mathiue, Taillandier, \& Lebrihi, 2004; Shetty, Hald, \& Jespersen, 2007) and the influence on regulation of the mycotoxin biosynthesis at a transcriptional level have been described (Gil-Serna, Patiño, Cortés, González-Jaén, \& Vazquez, 2011; Peromingo, Núñez, Rodríguez, Alía, \& Andrade, 2018) have also been previously described. Several yeasts such as $D$. hansenii, $H$. burtonii and $C$. zeylanoides were reported as strong inhibitors of $P$. nordicum growth in dry-cured ham and dry fermented sausage (Andrade et al., 2014; Nuñez et al., 2015; Virgili et al., 2012), but their effect on A. westerdijkiae remains without information. Bacteria of the Pediococcus and Lactobacillus genera have also been studied as potential BCAs against fungi and mycotoxins in several food matrices, with inhibiting effects being observed (Abrunhosa et al., 2014; Ngang et al., 2015; Pereira et al., 2016).

In the present study, the mechanisms of action of the yeast $C$. zeylanoides and of a commercial starter culture used for sausage fermentation on growth and OTA production by $P$. nordicum and $A$. westerdijkiae were tested. The results obtained for $P$. nordicum growth showed that the incorporated live cells reduced fungal growth in HM, whereas cell broth and dead cells significantly stimulated fungal growth in both media. For $P$. nordicum, growth patterns are similar for both media suggesting that cell broth or a cell component can be exerting the stimulation effect. In respect to OTA production, $P$. nordicum produced detectable levels only in HM. While the incorporation of live cells significantly stimulated OTA production, a significant decrease was observed for both cell broth and incorporated dead cells. No significant effect was observed on OTA production in diffusible and volatile tests. Direct contact between the starter culture and the fungus seems to exert a significant effect on the fungus, maybe as a result of competitive exclusion, based on competition for nutrient and space (Andrade et al., 2014; Hernández-Montiel et al., 2010; Zhao et al., 2008). This stress, while reducing fungal growth, seems to induce secondary metabolism with consequent mycotoxin production, as reported frequently (Vipotnik et al., 2017). In fact, fungal secondary metabolism is strongly stimulated by sub-optimal conditions like nutrient depletion or metabolites produced by other organisms. Since OTA is inhibited by cell broth and by dead cells we can assume that the starter metabolites potentially responsible for OTA induction are only produced as response to the presence of the fungus in co-culture with live starter cells. In the cell broth and in contact with dead cells, not only starter metabolites are not produced, but also extra nutrients are being offered to the fungus, thus reducing fungal stress with consequent increased growth and decreased OTA production. In a biocontrol test with $D$. hansenii against $P$. nordicum, Andrade et al. (2014) compared the effect of cell-free supernatants with those from live cells and concluded that the main mode of the antagonistic activity was based on competition for nutrients and space and, to a minor extent, the production of extracellular compounds such as volatile compounds or killer proteins.

In the case of $A$. westerdijkiae, there was no significant effect of the starter culture on fungal growth between control and test conditions and also between treatments. On the other hand, a significant stimulation of OTA production in both TSM and HM occurred with the incorporation of live cells and in the volatiles test. The direct contact of 


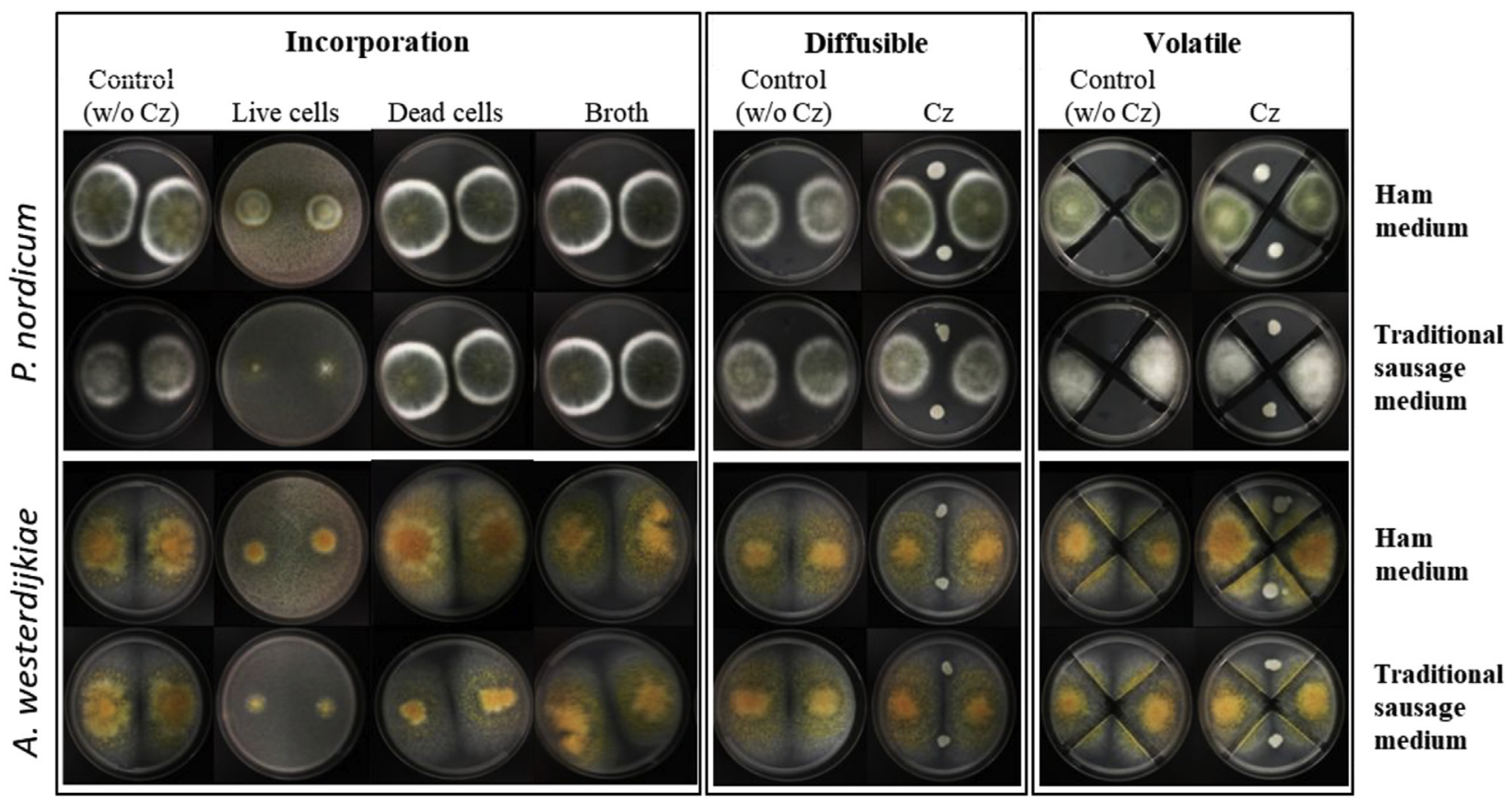

Fig. 1. Growth of $P$. nordicum and A. westerdijkiae in co-culture with $C$. zeylanoides, cultured in ham and traditional sausage media at $20{ }^{\circ} \mathrm{C}$.

live starter cells seems to have a significant impact on A. westerdijkiae, which is stronger in TSM. This could be explained by the fact that the starter culture is more adapted to this matrix assuming higher or faster growth, and consequently stronger effect in this medium. Cell supernatant and dead cells do not seem to exert any type of effect on $A$. westerdijkiae. On the contrary, volatile compounds being produced by the starter had a significant negative impact by increasing OTA production by this fungus.

Growth data for the incorporation test for both fungi are in

\section{P. nordicum}
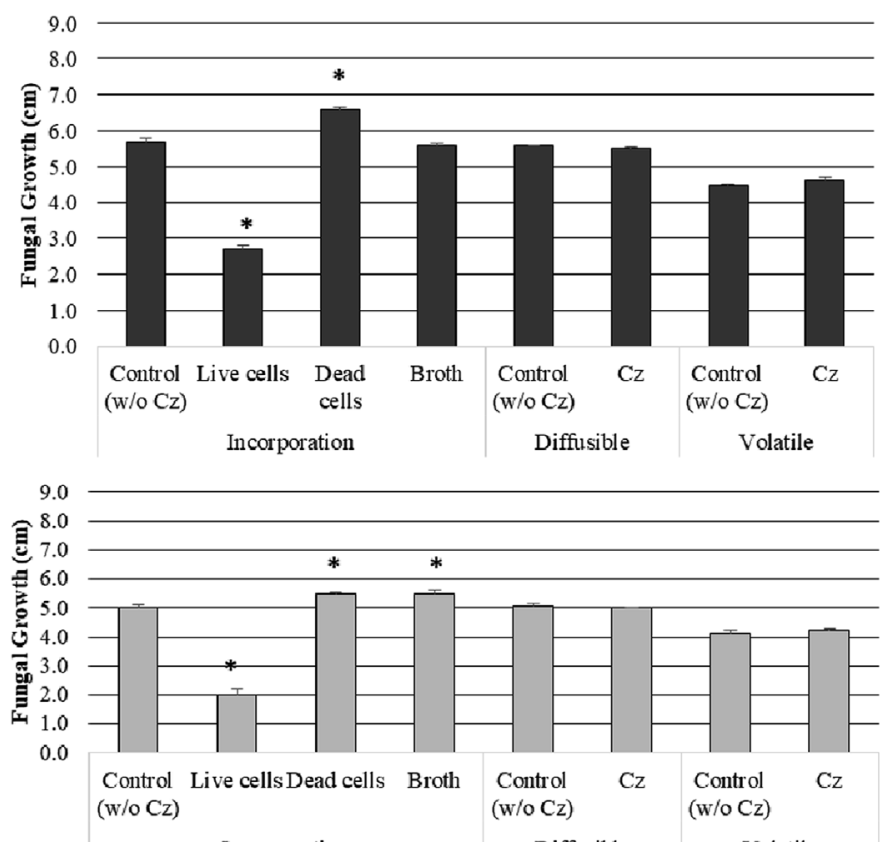

Incorporation

Volatile

Co-culture with C. zeylanoides

agreement with the results previously obtained (Meftah et al., 2018), where the incorporation of live cells significantly inhibited $P$. nordicum and $A$. westerdijkiae growth in both media. These effects on growth are similar to those registered and discussed for the starter culture.

As previously demonstrated, $P$. nordicum does not produce detectable amounts of OTA in TSM (Meftah et al., 2018). However, in HM it produced $123 \mathrm{ng} / \mathrm{g}$. C. zeylanoides inhibited significantly OTA production by $P$. nordicum under three test conditions: incorporation of live cells, cell broth and diffusion. Since no OTA was detected in the control
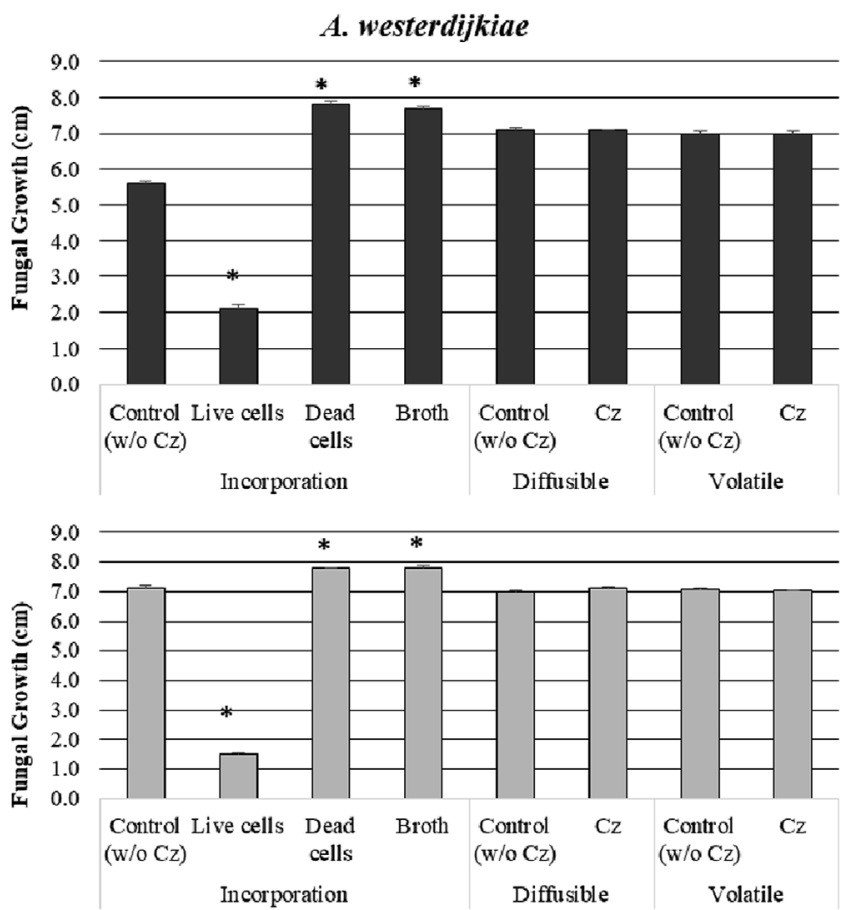

Co-culture with C. zeylanoides

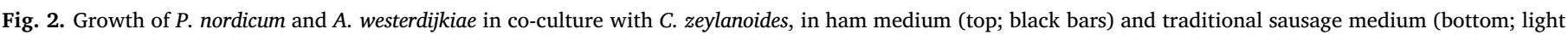

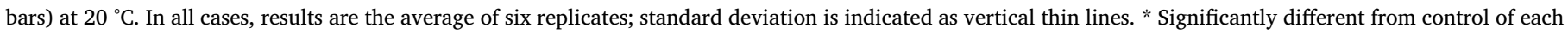
situation (without $C$. zeylanoides), $p<0.05$. 

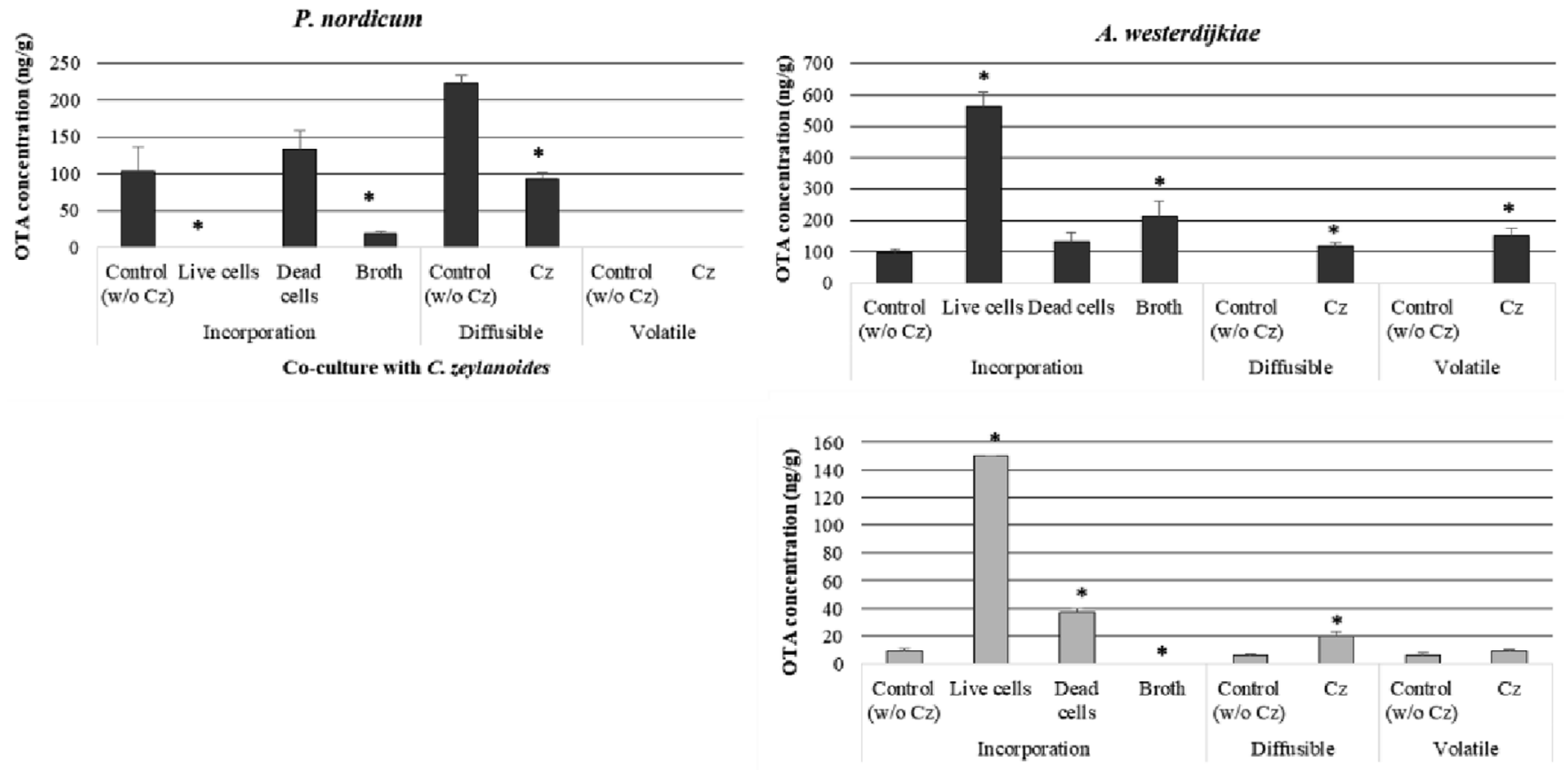

Co-culture with $C$. zeylanoides

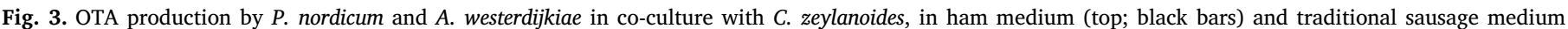

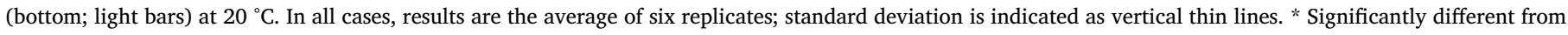
control of each situation (without $C$. zeylanoides), $\mathrm{p}<0.05$.

\section{P. nordicum}
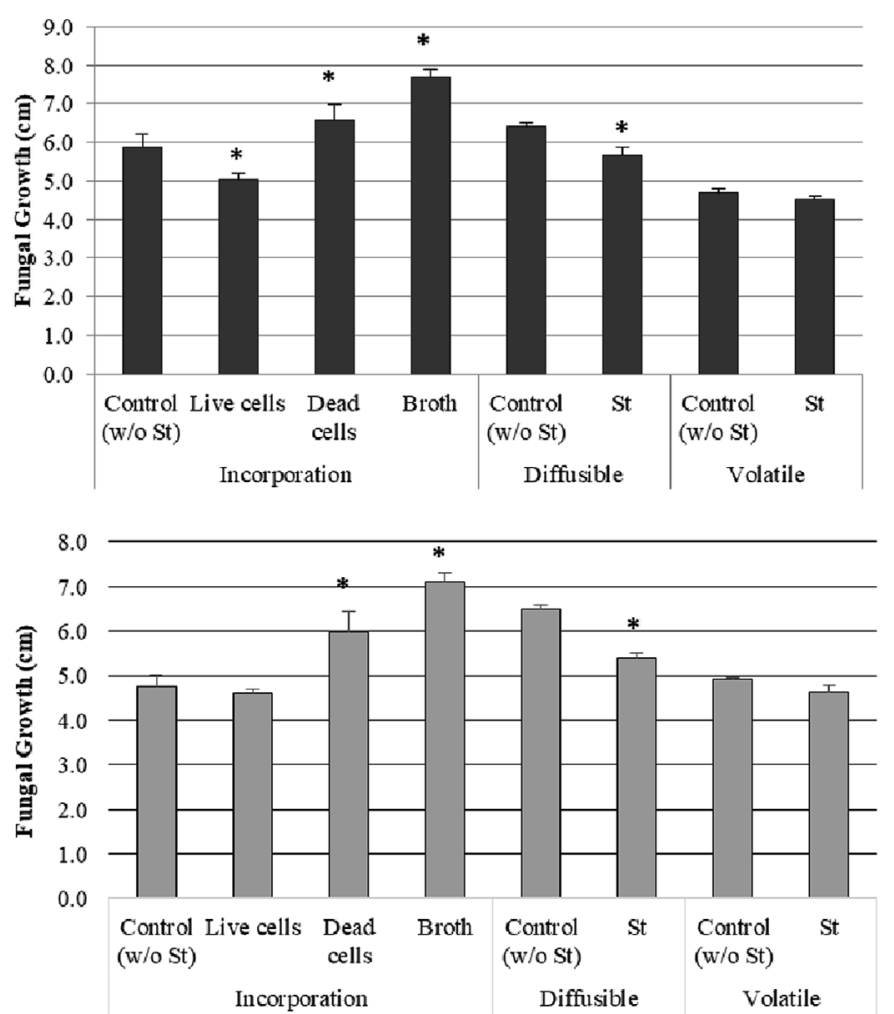

Co-culture with starter culture
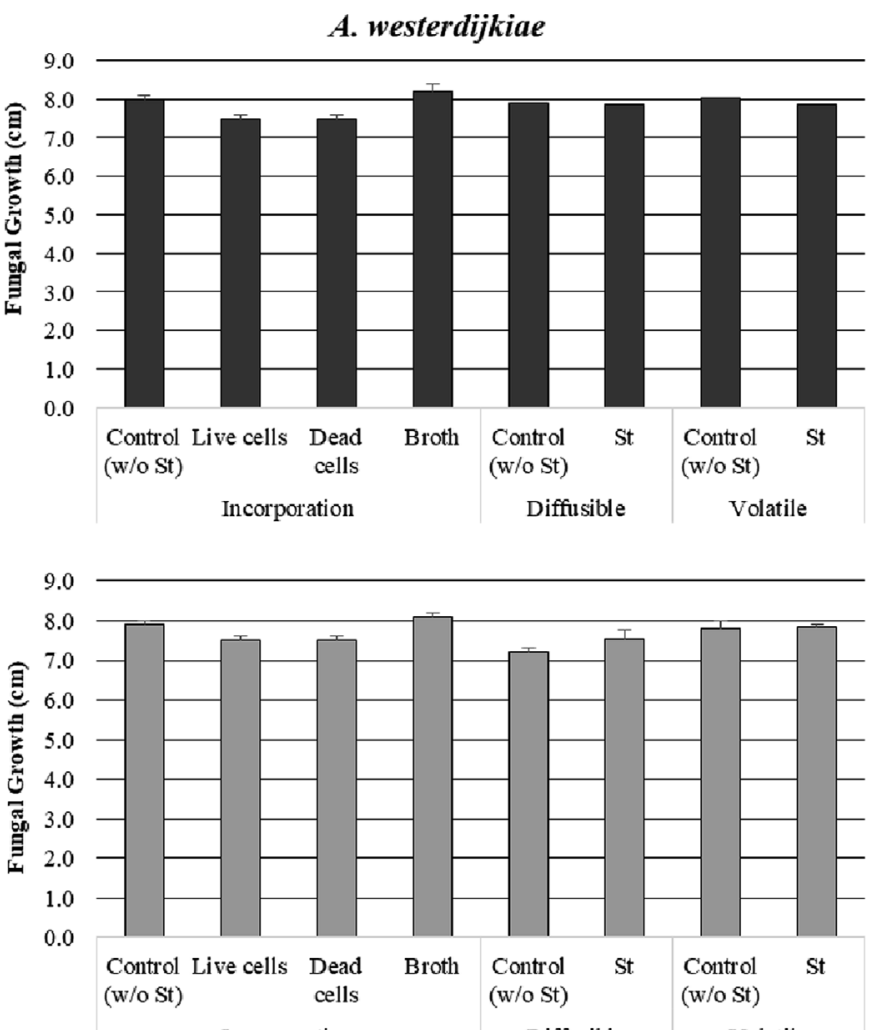

Incorporation
Volatile

Co-culture with starter culture

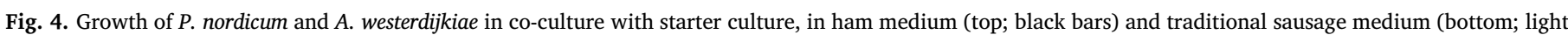

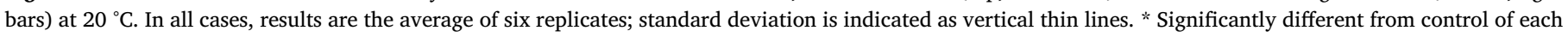
situation (without starter culture), $p<0.05$. 


\section{P. nordicum}

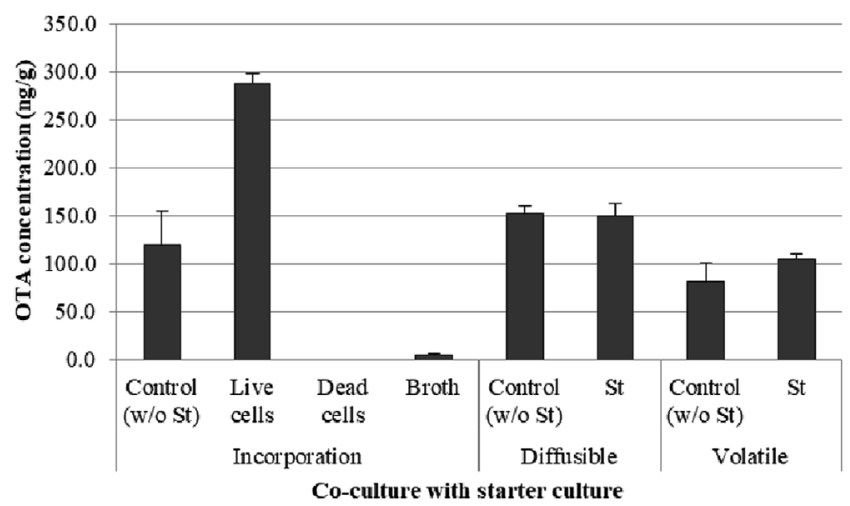

Co-culture with starter culture
A. westerdijkiae

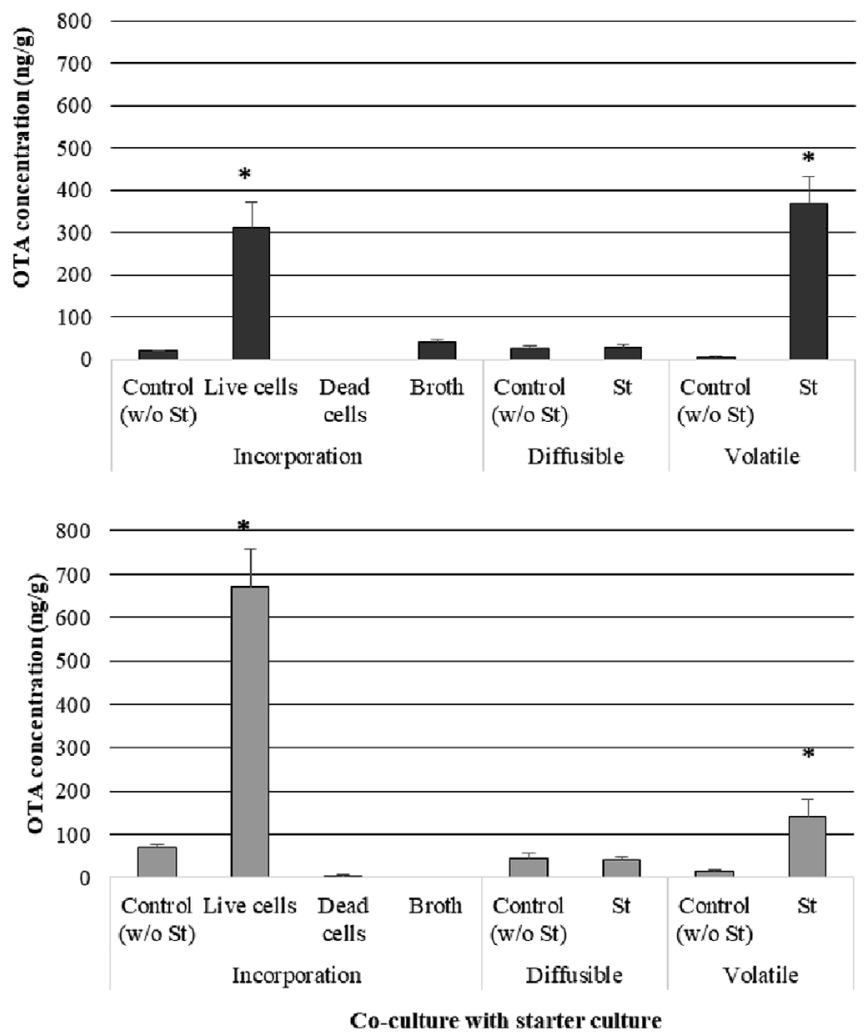

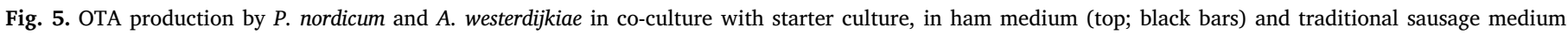

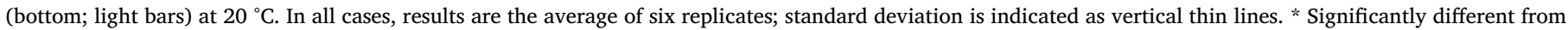
control of each situation (without starter culture), $\mathrm{p}<0.05$.

of the volatiles test, we cannot conclude about the effect of volatile compounds on OTA production. Contrary to the effect of the starter, where OTA was stimulated by living cells, $C$. zeylanoides inhibited both growth and OTA, and the effect seems to be exerted by extrolites produced $C$. zeylanoides. Since the difference in OTA levels between incorporated cells and cell broth is not significant, it seems like the inhibiting effect results from extrolites produced by the yeast independently of direct contact between both organisms. These extrolites seem to be produced by the yeast and diffused towards the fungus. This effect is seen by the reduced amount of OTA in the diffusible test. For this test, the inhibitory effect is not as strong as the previously described, which leads to the conclusion that the extrolites are reaching the fungus at limited concentrations by diffusion throughout the medium.

For $A$. westerdijkiae strong and significant stimulation is observed by direct contact in both media. In HM, $C$. zeylanoides seems to have cumulative effect of direct contact and diffusible compounds being produced in the medium, independently of the presence of the fungus seen by stimulation by cell broth-, effect of cell structural compounds determined by incorporation of dead cells - and volatiles. On the other hand, in TSM, low amounts of OTA are generally produced in all test conditions $(<38 \mathrm{ng} / \mathrm{g}$ ) except for incorporation of live cells. Even though statistical analysis determines significant differences between tests, we consider that no test clearly justifies stimulation except for direct contact between $A$. westerdijkiae and $C$. zeylanoides.

Mechanisms involved in the way microorganisms affect growth and OTA production ability of $P$. nordicum and $A$. westerdijkiae need to be clarified in order to optimise their applications in meat products. The present study shed some light on the mechanisms underlying the effect of the test organisms on growth and OTA production by the two fungi. Direct contact and simultaneous growth of test organisms were the mechanisms more significantly involved in fungal responses. While live cells of the native yeast Candida zeylenoides exert an expected inhibitor effect on $P$. nordicum toxigenic potential, the opposite effect is shown for $A$. westerdijkiae. The inhibitor effect on one fungus and stimulation of the other one is disturbing and could obstruct the use of microorganisms as BCAs. On the other hand, the commercial starter culture, which is widely used for meat fermentation processes, stimulated OTA production by both fungi. This effect is of major concern, and requires further attention.

\section{Acknowledgements}

This work was supported by the Foundatiion for Science and Technology (FCT, Portugal) and FEDER under Programme PT2020 for financial support to CIMO [UID/AGR/00690/2019].

\section{References}

Abrunhosa, L., Inês, A., Rodrigues, A. I., Guimarães, A., Pereira, V. L., Parpot, P., et al. (2014). Biodegradation of ochratoxin A by Pediococcus parvulus isolated from Douro wines. International Journal of Food Microbiology, 188, 45-52.

Andrade, M. J., Thorsen, L., Rodríguez, A., Córdoba, J. J., \& Jespersen, L. (2014). Inhibition of ochratoxigenic moulds by Debaryomyces hansenii strains for biopreservation of dry-cured meat products. International Journal of Food Microbiology, 170, 70-77.

Bejaoui, H., Mathiue, F., Taillandier, P., \& Lebrihi, A. (2004). Ochratoxin A removal in synthetic and natural grape juices by selected oenological Saccharomyces strains. Journal of Applied Microbiology, 97, 1038-1044.

Day, A., Schneider, C., \& Schneider, B. L. (2004). Chapter 6 - yeast cell synchronization. Methods in Molecular Biology, 241, 55-76.

Farbo, M. G., Urgeghe, P. P., Fiori, S., Marceddu, S., Jaoua, S., \& Migheli, Q. (2016). Adsorption of ochratoxin A from grape juice by yeast cells immobilised in calcium alginate beads. International Journal of Food Microbiology, 217, 29-34.

Fialho, M. B., Toffano, L., Pedroso, M. P., Augusto, F., \& Pascholati, S. F. (2009). Volatile organic compounds produced by Saccharomyces cerevisiae inhibit the in vitro 
development of Guignardia citricarpa, the causal agent of citrus black spot. World Journal of Microbiology and Biotechnology, 2, 925-932.

Fiori, S., Urgeghe, P. P., Hammami, W., Razzu, S., Jaoua, S., \& Migheli, Q. (2014). Biocontrol activity of four non- and low-fermenting yeast strains against Aspergillus carbonarius and their ability to remove ochratoxin A from grape juice. International Journal of Food Microbiology, 189, 45-50.

Gil-Serna, J., Patiño, B., Cortés, L., González-Jaén, M. T., \& Vazquez, C. (2011). Mechanisms involved in reduction of ochratoxin A produced by Aspergillus westerdijkiae using Debaryomyces hansenii CYC 1244. International Journal of Food Microbiology, 151, 113-118.

Hernández-Montiel, L. G., Ochoa, J. L., Troyo-Diéguez, E., \& Larralde-Corona, C. P. (2010). Biocontrol of postharvest blue mold (Penicillium italicum Wehmer) on Mexican lime by marine and citrus Debaryomyces hansenii isolates. Postharvest Biology and Technology, 56, 181-187.

Iacumin, L., Manzano, M., Andyanto, D., \& Comi, G. (2017). Biocontrol of ochratoxigenic moulds (Aspergillus ochraceus and Penicillium nordicum) by Debaryomyces hansenii and Saccharomycopsis fibuligera during speck production. Food Microbiology, 62, 88-195.

Marquina, D., Barroso, J., Santos, A., \& Peinado, J. M. (2001). Production and characteristics of Debaryomyces hansenii killer toxin. Microbiol Res. 156, 387-391.

Masih, E. I., \& Paul, B. (2002). Secretion of beta-1,3-glucanases by the yeast Pichic membranifaciens and its possible role in the biocontrol of Botrytis cinerea causing grey mold disease of the grapevine. Current Microbiology, 44, 391-395.

Masoud, W., Poll, L., \& Jakobsen, M. (2005). Influence of volatile compounds produced by yeasts predominant during processing of Coffea arabica in East Africa on growth and ochratoxin A (OTA) production by Aspergillus ochraceus. Yeast, 22, 1133-1142.

Meftah, S., Abid, S., Dias, T., \& Rodrigues, P. (2018). Effect of dry-sausage starter culture and endogenous yeasts on Aspergillus westerdijkiae and Penicillium nordicum growth and OTA production. Lebensmittel-Wissenschaft und -Technologie- Food Science and Technology, 87, 250-258. https://doi.org/10.1016/j.lwt.2017.08.090.

Merla, C., Andreoli, G., Garino, C., Tosi, G., Guglielminetti, M. L., Moretti, A., et al. (2018). Monitoring of ochratoxin A and ochratoxin- producing fungi in traditional salami manufactured in Northern Italy. Mycotoxin Research, 34, 107-116.

Ngang, J. J. E., Germaine, Y., Sylvain, L. S. Y., Kouebou, C. P., Fanche, S. A., Tsochi, D. L. K., et al. (2015). Antifungal properties of selected lactic acid bacteria and application in the biological control of ochratoxin A producing fungi during cocoa fermentation.
Biocontrol Science and Technology, 25, 245-259.

Nuñez, F., Lara, M. S., Peromingo, L., Delgado, J., Sanchez-Montero, L., \& Andrade, M. J. (2015). Selection and evaluation of Debaryomyces hansenii isolates as potential bioprotective agents against toxigenic penicillia in dry-fermented sausages. Food Microbiology, 46, 114-120.

Pereira, M., Beux, M., Pagnoncelli, B., Soccol, V. T., Rodrigues, C., \& Soccol, C. R. (2016) Isolation, selection and evaluation of antagonistic yeasts and lactic acid bacteria against ochratoxigenic fungus Aspergillus westerdijkiae on coffee beans. Letters in Applied Microbiology, 62, 96-101.

Peromingo, B., Núñez, F., Rodríguez, A., Alía, A., \& Andrade, M. J. (2018). Potential of yeasts isolated from dry-cured ham to control ochratoxin A production in meat models. International Journal of Food Microbiology, 268, 73-80.

Rodriguez, A., Bernaldez, V., Rodriguez, M., Andrade, M. J., Nuñez, F., \& Cordoba, J. J. (2015). Effect of selected protective cultures on ochratoxin A accumulation in drycured Iberian ham during its ripening process. LWT-Food Sci. Technol. 60, 923-928.

Shetty, P. H., Hald, B., \& Jespersen, L. (2007). Surface binding of aflatoxin B1 by Saccharomyces cerevisiae strains with potential decontaminating abilities in indigenous fermented foods. International Journal of Food Microbiology, 113, 41-46.

Simoncini, N., Virgili, R., Spadola, G., \& Battilani, P. (2014). Autochthonous yeasts as potential biocontrol agents in dry-cured meat products. Food Control, 46, 160-167.

Taczman-Brückner, A., Mohácsi-Farkas, C., Balla, C., \& Kiskó, G. (2005). Mode of action of Kluyveromyces lactis in biocontrol of Penicillium expansum. Acta Alimentaria Hungarica, 34, 153-160.

Vipotnik, Z., Rodríguez, A., \& Rodrigues, P. (2017). Aspergillus westerdijkiae as a major ochratoxin A risk in dry-cured ham based-media. International Journal of Food Microbiology, 241, 244-251.

Virgili, R., Simoncini, N., Toscani, T., Leggieri, M. C., Formenti, S., \& Battilani, P. (2012) Biocontrol of Penicillium nordicum growth and ochratoxin a production by native yeasts of dry cured ham. Toxins, 4, 68-82.

Zain, M. (2011). Impact of mycotoxins on humans and animals. J Saudi Chem Soc, 15, 129-144.

Zhao, Y., Tu, K., Shao, X., Jing, W., \& Su, Z. (2008). Effects of the yeast Pichia guilliermondii against Rhizopus nigricans on tomato fruit. Postharvest Biology and Technology, 49, 113-120. 